\title{
LOTÓFAGOS (ODISSEIA IX, 82-104): COMIDA FLORAL FÁCIL E RISCO DE DESISTÊNCIA ${ }^{1}$
}

Teodoro Rennó Assunção*

RESUMO: Este artigo propõe uma tradução e um comentário do episódio dos Lotófagos na Odisseia (IX, 82-104), atentando tanto para sua organização interna enquanto episódio de viagem com uma cena típica de hospitalidade (resumida apenas à oferta de comida), quanto para sua posição e especificidade no conjunto das viagens maravilhosas de Odisseu (cantos IX a XII) e no conjunto da Odisseia. Ele tenta definir os significados possíveis de lōtós ("lótus"), tais como apresentados por Heródoto e Teofrasto, em confronto com os poucos dados presentes na Odisseia (convergindo em ser ele uma planta não cultivada e colhida), e - o que é mais importante - tenta definir também os efeitos do consumo do lótus, que são como os de uma droga perigosa (como o haxixe, o ópio ou a mescalina) que suprime a vontade de agir, ameaçando retrospectivamente o retorno de Odisseu e a própria narrativa da Odisseia.

PALAVRAS-CHAVE: Lotófagos; Odisseia; comida floral fácil; risco de desistência.

\section{LOTOPHAGES (ODYSSÉE IX, 82-104): NOURRITURE DE FLEUR, FACILE, ET RISQUE D'ABANDON}

RÉSUMÉ: Cet article propose une traduction et un commentaire de l'épisode des Lotophages dans l'Odyssée (IX, 82-104), en faisant attention aussi bien à son organisation interne en tant qu'épisode de voyage avec une scène typique d'hospitalité (réduite seulement à l'offre de nourriture), qu'à sa position et spécificité dans l'ensemble des voyages merveilleux d'Ulysse (chants IX à XII) et dans l'ensemble de l'Odyssée. Il essaie de définir les sens possibles de lòtós ("lotus"), tels que présentés par Hérodote et Théophraste, confrontés avec le peu de données présentes dans l'Odyssée (convergeant sur le fait que celui-ci est une plante non cultivée et cueillie),

\footnotetext{
${ }^{1}$ Uma parte deste artigo (basicamente a seção B) foi apresentada no XIX Congresso da Sociedade Brasileira de Estudos Clássicos / I Simpósio LusoBrasileiro de Estudos Clássicos, em Brasília, ocorrido de 8 a 12 de julho de 2013; e uma outra parte (basicamente a seção A), no evento Gêneros literários e filosofia na Grécia antiga, no IFAC da UFOP, em Ouro Preto, no dia 12 de setembro de 2014. O autor agradece a revisão atenta e cuidadosa de Tatiana Ribeiro, assim como a de Antonio Orlando de O. Dourado-Lopes.
}

* Faculdade de Letras da Universidade Federal de Minas Gerais. 
et - ce qui est plus important - il essaie de définir aussi les effets de l'ingestion du lotus, qui sont comme ceux-là d'une drogue dangereuse (telle que le haschisch, l'opium ou la mescaline) qui supprime la volonté d'agir, menaçant - d'une manière rétrospective - le retour d'Ulysse et le récit lui-même de l'Odyssée.

MOTS-CLÉS: Lotophages; Odyssée; nourriture de fleur; facile; risque d'abandon.

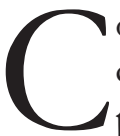

omo primeiro e elementar exercício interpretativo deste breve episódio da Odisseia que, a partir de seus temas principais, comentarei a seguir, proponho uma tradução provisória do texto grego homérico, sem nenhuma preocupação com um esquema rítmico correspondente, ou próximo, em português, ao hexâmetro dactílico, mas apenas com uma básica precisão semântica, que (não envergonhada de uma relativa literalidade) é vocabular e sintática, mas nos limites do verso, que é conservado como unidade ou linha (para permitir uma localização mais exata do texto grego), ${ }^{2}$ ainda que livre de qualquer padrão rítmico constante.

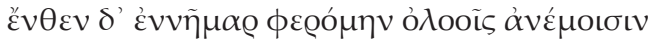

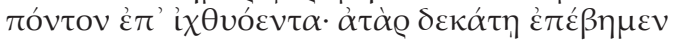

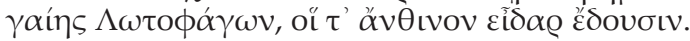

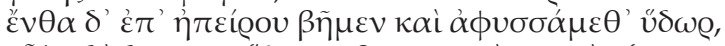

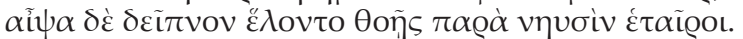

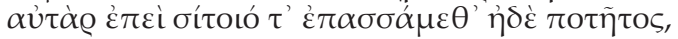

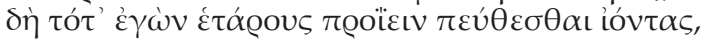

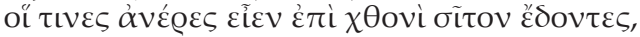

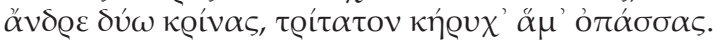

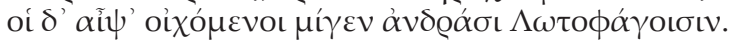

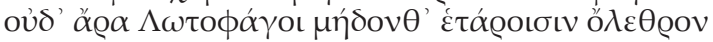

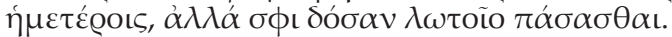

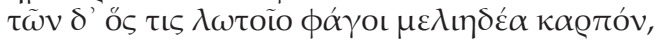

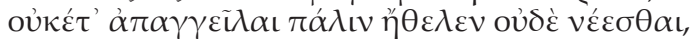

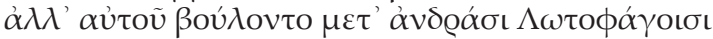

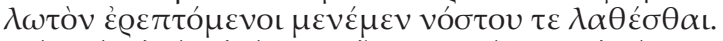

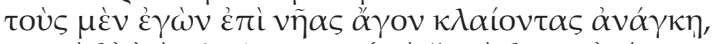

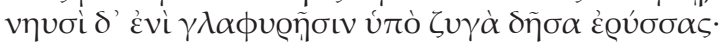

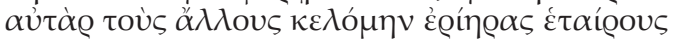

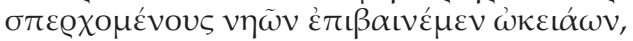

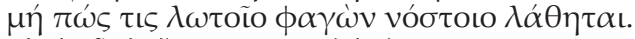

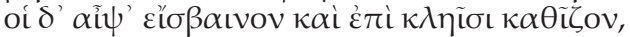

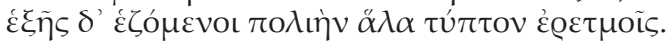
E daí, durante nove dias, fui levado por destrutivos ventos sobre o mar piscoso; e então no décimo desembarcamos na terra dos Lotófagos, que comem uma comida floral. E aí sobre o continente caminhamos e retiramos água,

\footnotetext{
${ }^{2}$ Adoto aqui o texto grego da Odisseia estabelecido por Helmut van Thiel para a edição da Olms (Homeri Odyssea, 1991), e para cotejo o estabelecido por Thomas W. Allen para a coleção "Oxford Classical Texts" (Homeri Opera tomus III, 1987).
} 
e rápido almoçaram junto às ágeis naus, os companheiros. Mas depois que partilhamos tanto do pão quanto da bebida, eu enviei então companheiros para irem se informar sobre quais seriam os homens que sobre este solo comem o pão, escolhendo dois homens, e enviando um terceiro como arauto.

E estes, indo rápido, se misturaram aos homens lotófagos. E não pensaram os Lotófagos morte para os companheiros nossos, mas lhes deram do lótus para provar, partilhando. E destes o que tivesse comido do lótus o fruto sabor-de-mel, não mais de novo queria dar notícias suas, nem retornar, mas ali tinham vontade de, com os homens lotófagos o lótus pastando, permanecer e do retorno se esquecer. A estes, que choravam, eu conduzi até as naus por força, e nas naus côncavas sob os bancos os prendi, arrastando; e então aos outros ordenei, aos leais companheiros, que, se apressando, embarcassem nas naus rápidas, para que nenhum, do lótus comendo, do retorno se esquecesse. E estes, rápido, embarcaram e junto aos toletes se sentaram, e, em ordem sentados, o gris mar salso bateram com remos.

(Odisseia IX, 82-104)

\section{A. Os SIGNIFICADos DE "LÓTUs"}

Mesmo sabendo que também este episódio de viagem, o primeiro das viagens maravilhosas (ou em um mundo não-humano) de Odisseu, é composto não só por fórmulas ajustáveis na unidade do hexâmetro dactílico, como também por micro-cenas típicas (ou temas), que são unidades narrativas básicas que compõem, por sua vez, unidades maiores, ${ }^{3}$ tentaremos, para começar, uma breve discussão do sentido do termo grego lōtós, que traduzimos aqui tradicionalmente por "lótus", e que é fundamental na definição deste povo como "Lotófagos" (Lōtophágor), ou seja: "Comedores de lótus". A dificuldade de precisar o sentido se deve ao fato de que o nome grego lōtós, como o português "lótus" (ou "lódão"), é polissêmico, fato já reconhecido por Teofrasto em sua História (ou Investigação) das plantas: "Certas plantas existem sob múltiplas formas que, por assim dizer, são quase homônimas, como o lótus; dele são muitas as espécies, que se diferenciam pelas folhas, os caules, as flores e os frutos, e entre as quais está também o chamado meliloto." (História das plantas, VII, 15, 3, tradução minha). Ora, o "meliloto" (Melilotus), como planta leguminosa da família das

\footnotetext{
${ }^{3}$ Apenas como indicações básicas, para uma definição de "cena típica" ("typische Scene") em Homero, ver a obra fundamental de Walter Arend, Die typische Scenen bei Homer (Arend, 1933), e para uma de "tema" ("theme") ver o capítulo 4, "The Theme", da obra comparativa basilar de Albert B. Lord, The Singer of Tales (Lord, 2000, p. 68-98), e ainda o artigo "Type-Scenes and Homeric Hospitality" de Mark W. Edwards (1975), assim como - mais especificamente sobre a Odisseia - o capítulo 7, "Thematic Structure in the Odyssey", de Traditional Oral Epic. The Odyssey, Beowulf, and the Serbo-Croatian Return Song de John Miles Foley (1990, p. 240-277).
} 
papilionídeas, se aproxima do "lótus" (Lotus), na sua segunda acepção (segundo o Dicionário Houaiss), ${ }^{4}$ também como planta leguminosa da família das papilionídeas, que pode igualmente ser forrageira (isto é: servir para pasto). Este sentido coincidentemente é o que permitiria compreender melhor os outros dois usos de lòtós em Homero como uma planta para pastagem de cavalos (Ilíada II, 776, junto com o "aipo dos pântanos", na expressão lōtòn ereptómenoi, "o lótus pastando"; Odisseia IV, 603, junto com a "junça", o "trigo", a "espelta" e a "cevada", como pasto para cavalos) e que impediria o uso do termo "lódão" (como o faz Frederico Lourenço para estas duas outras ocorrências) para traduzi-lo, já que nenhum dos sentidos possíveis de "lódão" é o de uma planta forrageira. Esta acepção também pode se integrar em uma caracterização mais genérica - e decisiva aqui - dos Lotófagos como um povo que "não come pão", por não praticar a agricultura (e nem a pecuária), e que se alimenta (como os animais, donde a retomada da expressão "o lótus pastando") apenas do que a terra lhes oferece espontaneamente. Ela apenas dificulta uma compreensão mais literal da expressão que define primeiramente o "lótus" - na primeira caracterização dos Lotófagos exatamente por sua comida - como "comida floral" (ánthinon eîdar).

Já Heródoto, quando propõe a localização geográfica dos Lotófagos (mas sem nenhuma referência à Odisseia) em um promontório que dá para a região dos Gindanes (uma região na costa do norte da África, nas proximidades da pequena Syrtis e da ilha de Djerba, cf. Ballabriga, 1998, p. 75), define da seguinte maneira o lōtós ("lótus", na quinta acepção do Dicionário Honaiss): "Um promontório que avança para o mar diante (da região) dos Gindanes é habitado pelos Lotófagos, que vivem comendo unicamente o fruto do lótus. O fruto do lótus é, quanto ao tamanho, como o do lentisco, e, quanto à doçura, parecido com o fruto da palmeira. Os Lotófagos fazem também um vinho deste fruto." (Histórias IV, 177, tradução minha). A descrição análoga de Teofrasto é um pouco mais detalhada: "E do lótus a árvore toda é caracteristicamente de bom tamanho, igual ou pouco menor que a de uma pereira; ela tem uma folha recortada como a do carrasqueiro, e sua madeira é negra. Dela são múltiplas as espécies, que se diferenciam pelos frutos. O fruto é do tamanho de uma fava, e amadurece, como as uvas, mudando as cores. Ele cresce, como as bagas dos mirtos, junto uns dos outros, compactamente sobre os ramos. Sendo comido, o fruto dos chamados Lotófagos é doce, saboroso, inofensivo e, ainda, bom para o ventre; mas o fruto sem caroço - pois existe também uma tal espécie - é mais saboroso, e dele fazem também um vinho. A árvore é abundante e dá muitos frutos. Ao menos dizem que o exército (em campanha) de Ofelas, quando caminhava para Cartago, dela se alimentou durante muitos dias, quando faltaram víveres." (História das plantas IV, 3, 1-2, tradução minha). É a partir desta definição de Heródoto e desta descrição de Teofrasto, que Lineu, por sua vez, identificará este "lótus" como a "jujuba" ou o "fruto da jujubeira" e o denominará como Zišsphus lotus. Também neste

\footnotetext{
${ }^{4}$ Estarei citando aqui, na sequência, a primeira edição do Dicionário Houaiss da língua portuguesa, e, mais particularmente, as palavras "lótus" e "lódão" (cf. Houaiss et alii, 2001, p. 1784 e 1777).

${ }^{5}$ É curioso como o Greek-English Lexicon de Liddell-Scott-Jones, após elencar três diferentes sentidos principais possíveis para lōtós: "I. fodder plants (...). II. Nile water-lily, Egyptian lotus (...). III. of trees found in Lybia (...)", distingue, no último caso, dois tipos, o segundo dos quais seria precisamente o
} 
caso é difícil imaginar o que na "jujuba" poderia corresponder literalmente a uma "comida floral", ainda que quanto à doçura a comparação com a tâmara possa corresponder bem à definição do "fruto do lótus" (lōtôio karpón) como "sabor-de-mel" (melièdéa). Mas, assim como no caso do "lótus" como planta forrageira, a "jujuba" também não pressuporia a agricultura e seria apenas colhida, tal como a natureza a oferece, pelos Lotófagos.

No entanto, ao narrar o modo como os Egípcios que habitam os pântanos (junto ao Nilo) encontraram uma alimentação mais simples ou barata, Heródoto descreve um outro tipo de "lótus": "Quando o rio está cheio e as planícies se tornam um mar, brotam na água muitos lírios (krínea), que os Egípcios chamam de lótus (lötón). E quando os colhem, secam-nos ao sol, e depois, pilando o que vem do meio do lótus, que é parecido à papoula, fazem dele pães assados no fogo. Também a raiz deste lótus é comestível e bastante doce, sendo redonda, e, quanto ao tamanho, como uma maçã." (Histórias II, 92, tradução minha). Esta ninfeácea, também descrita por Teofrasto (cf. História das plantas IV, 8, 9-11), será depois definida botanicamente como Nymphaea lotus ("lótus" na acepção 1.1 do Dicionário Houaiss), sendo que o seu ovário e as suas sementes, ou seja: "o que vem do meio do lótus", poderiam de algum modo ser interpretados como a sua parte floral, que, secada e pilada, será transformada em pães (o que, como bem sabemos, não é especificado no caso do "lótus" dos Lotófagos da Odisseia). Mas é apenas a raiz que, dificilmente compreensível como propriamente um "fruto", poderia corresponder em termos de gosto ao "sabor-de-mel". Também neste caso poderíamos pensar em uma alimentação vegetariana, que não implica a agricultura e o trabalho da terra (nem a pecuária), mas apenas a colheita de "flores" (ou "frutos", pensados, como o karpós grego, no sentido mais geral daquilo que se colhe) de lírios aquáticos que brotam quando da cheia do Nilo, tornando possível uma caracterização dos Lotófagos como meros colhedores. E, enfim, ainda que não os denominando como "lótus", Heródoto descreve, na imediata sequência da última passagem, outros lírios (krínea) aquáticos que podem também fornecer uma comida fácil: "E existem também outros lírios, parecidos às rosas, que nascem também no rio, dos quais o fruto, brotando junto em um outro cálice, nasce a partir da raiz, o mais semelhante possível, quanto à forma, a um favo de vespas; neste nascem numerosas e comestíveis sementes do tamanho de um caroço de

Zisyphus Lotus, reconhecido como o deste episódio da Odisseia: “1. nettle-tree, Celtis australis (...). 2. Tree growing among the Lotophagi, Zi氵yphus Lotus, lötô̂... melièdéa karpón Od. 9.94, cf. Hdt. 2.96, 4.177, Thphr. HP 4.3.1-4, Plb. I2.2.2.” (Liddell-Scott-Jones, 1977, p. 1070). Uma mesma identificação, após o reconhecimento da polissemia básica do termo, é feita pelo Dictionnaire étymologique de la langue grecque de Pierre Chantraine: "nom de divers végétaux, plantes fourragères, trèfles et mélilots, trèfle fraise, Lotus corniculatus (...), nom de plantes d'Afrique, le lótus aquatique d'Égypte, Nymphaea lotus (Hdt.); arbres divers, jujubier sauvage, Zizyphus Lotus, c'est le lotus des Lotophages dans l'Odyssée; aussi le micocoulier, Celtis Australis (...)." (Chantraine, 1984, p. 654, negritos meus). A etimologia proposta por Chantraine é, neste caso, de pouca ou nenhuma utilidade: "Et.: Terme méditérranéen d'origine obscure. Lewy, Fremdwörter 46, après Muss-Arnolt, évoque hébr. lōt traduit par stakté (LXX Ge. 37, $25 ; 43,11)$. Il s'agirait donc originellement d'un arbre distillant une huile, ce qui s'appliquerait, par exemple, au micocoulier." (Chantraine, 1984, p. 654). 
azeitona; e estas são comidas tanto frescas quanto secas." (Histórias II, 92, tradução minha). Esta espécie de ninfeácea aquática foi depois denominada botanicamente Nelumbo nucifera e, como a Nymphaea lotus, fornece uma comida fácil (a partir da semente, chamada também de "fava egípcia"), a ser apenas colhida e não pressupondo a agricultura nem o trabalho da terra (o que seria ainda extensível ao papiro, búblon, mencionado na imediata sequência, que cresce nos pântanos junto ao Nilo). ${ }^{7}$

Mesmo que não precisemos adotar a hipótese de Alain Ballabriga, no capítulo 2, "Du Nil au couchant", do livro Les fictions d'Homère, ${ }^{8}$ de que os Homéridas que deram forma final à Odisseia no século VI a. C. já conheciam algo sobre os diferentes tipos de "lótus" mencionados por Heródoto como naturais na costa do norte da África (e nem precisemos tampouco definir a terra dos Lotófagos odisseicos como geograficamente situada, tal como a Libia e o norte do Egito, nos confins ocidentais do Mar Mediterrâneo), pensamos ser possível extrair das informações mais precisas de Heródoto e Teofrasto sobre os diferentes tipos de "lótus" (sem que seja preciso escolher como o mais plausível um deles, como o Nymphaea lotus por Denys Page, ${ }^{9}$ ou simplesmente desconsiderá-las, como o faz Alfred Heubeck ${ }^{10}$ ) algumas características básicas que confirmam o "lótus" como uma planta basicamente não cultivada, cuja "flor" ou "fruto" pode ser colhida e transformada em comida, sem que os Lotófagos tenham que trabalhar a terra e praticar a agricultura, definindo-se negativamente como "vegetarianos" (em sentido lato, e não programático e religioso como para os pitagóricos e os órficos) que não comem o pão feito de trigo e nem a carne de animais domésticos sacrificáveis (já que não há também nenhuma menção da pecuária ou do sacrifício), e nem bebem também algum vinho (pois também esta bebida não é mencionada, e nenhuma outra, como no caso do vinho da jujuba por Heródoto).

6 “(...) Nelumbo nucifera, Gaertn. (Nelumbium speciosum, Willd.), qui est le lotus de l'Inde orientale et dont la graine, nommée parfois faba aegyptiaca (fève d'Egypte), est très appréciée en Extrême-Orient où elle passe notamment pour faciliter le sommeil." (Foucaud, 1962, p. 423).

${ }^{7}$ Deixaremos aqui de lado outros tipos de "lótus" também citados por autores antigos, mas que não são mencionados por Heródoto, como, por exemplo, o "lótus paliúro" (Paliurus Spina-Christi ou Ziziphus spina Christi), citado por Teofrasto, ou o lótus de Dioscórides, geralmente admitido como o Celtis Australis, e que constitui a segunda acepção do termo "lódão" no Dicionário Honaiss, ou ainda o Diospyros Lotus, a que provavelmente se refere Plínio, e que constitui a terceira acepção do termo "lótus" no Dicionário Houaiss. Ver para estas informações o artigo de A. Foucaud "Un petit problème d'histoire grecque: Lotus et Lotophage" (cf. Foucaud, 1962).

${ }^{8}$ Sobretudo os subcapítulos 2 a 5, cf. Ballabriga, 1998, p. 67-90.

9 "So I suppose that Egyptian Nymphaea was the diet of the real and remote ancestors of the fictious Lotus-Eaters of the Odyssey" (Page, 1973, p. 14).

10 “(...) the lotós plant, with its magical properties of suppressing the desire to return home, is symbolic of the insecurity of human existence poised precariously between the spheres of empirical reality and mythical unreality. It is, therefore, pointless to attempt, as so many scholars, both ancient and modern, have done, to identify either the lōtós plant itself or the country where it grows. In identifying the country as Little Syrtis (IV, 176 ff.), Hdt., and scholars after him, showed no understanding of the nature and function of poetry." (Heubeck, 1989, p. 18, negritos meus). 
Eles poderiam, assim, figurar, antes do pastor Polifemo, que também não conhece a agricultura (mas porque a terra produz por ela mesma o trigo, a cevada e as vinhas, cf. Odisseia IX, 108-111) e se alimenta (como certos Citas pastores e selvagens em Heródoto IV, 106) de leite, queijo e homens comidos crus (além do vinho sem mistura com água), ${ }^{11}$ um modo de vida bárbaro e primitivo (e talvez ainda mais primitivo do que o do Ciclope pastor, por ser apenas o da coleta ${ }^{12}$ ), que - nesta ótica homérica - se contrapõe a uma definição básica do humano como "comedor de pão" (e sacrificador de animais domésticos). Notemos também que, além da oferta de "lótus" (sem nenhuma especificação de sua coleta ou preparo culinário) para os três companheiros de Odisseu e um suposto consumo do "lótus" juntamente com eles, a narrativa de Odisseu não menciona nenhuma outra atividade dos Lotófagos.

Parece-me, assim, razoável, aproximar, como o faz Allain Ballabriga (cf. 1998, p. 72-75), o modo primitivo de vida dos Lotófagos colhedores de "lótus" daquele sugerido em Trabalhos e dias de Hesíodo por um aforismo enigmático que cita duas plantas não cultivadas e que podem ser colhidas, a malva e o asfódelo, certamente comida de pobres ou indigentes, ${ }^{13}$ em contraposição aos cereais que (escondidos pelos deuses) necessitam ser cultivados e pressupõem, portanto, o trabalho da terra (enquanto a raça ou linhagem de ouro se alimenta do "fruto farto" que a "lavoura dá-trigo", zeídōros ároura, e não uma terra selvagem, dá "espontaneamente", automátè, cf. versos 117-118, em uma versão mais positiva e idealizada dos primeiros tempos):

\footnotetext{
${ }^{11}$ Ver, para uma caracterização do pastoreio nômade (na antiga ideologia mediterrânea) como um modo de vida primitivo, o artigo de Brent Shaw "'Eaters of flesh, drinkers of milk': the ancient mediterranean ideology of the pastoral nomad" (Shaw, 1982/1983).

${ }^{12}$ Aristóteles, no livro I (8) da Política, estabelece uma hierarquia dos modos humanos de aquisição de víveres (conectados em cada caso a um modo de alimentação) a partir da natureza (e, portanto, sem levar em conta o comércio), do mais primitivo ao mais evoluído: o dos pastores, o dos caçadores (ou dos saqueadores e piratas), o dos pescadores e o dos agricultores (que é considerado o mais genérico para a espécie humana). Ora, ao definir o modo dos pastores, Aristóteles justifica porque eles estão no ponto mais baixo desta hierarquia (chamando em seguida a atenção também para o seu nomadismo):

"Os homens mais preguiçosos são pastores, pois a comida que os animais domésticos lhes fornecem lhes chega sem esforço e eles folgam; mas sendo necessário para os rebanhos mudar de lugar por causa das pastagens, os próprios homens são obrigados a acompanhá-los, como se eles cultivassem uma terra viva." (Aristóteles, Política I, 8, 1256a, 30-35, tradução minha, negritos meus). O que Aristóteles - que nem os menciona nesta escala - diria, então, da preguiça dos simples coletores de frutos de plantas não cultivadas?

${ }^{13}$ Em uma nota de pé de página (para "mallow and asphodel") de sua tradução para o inglês de Trabalhos e dias de Hesíodo, Glenn Most observa sucintamente: "Traditionally, the poor man's fare." (Hesiod, 2006, p. 91). Já Philippe Rousseau, no artigo "Instruire Persès - Notes sur l'ouverture des Travaux d'Hésiode", observa: "La mauve et l'asphodèle sont des plantes qu'on ne cultivait pas, mais dont peut-être on se nourrissait dans les périodes de famine: un aliment, au mieux, de l'indigence êxtreme. Elles ne font pas partie du bios que les dieux tiennent cachés pour que les hommes l'arrachent à la terre par leur travail.” (Rousseau, 1966, p. 156).
} 
Tolos, não sabem quão maior é a metade do que o todo nem quão grande valia há na malva e no asfódelo.

Pois deuses ocultaram e seguram o sustento dos homens.

De outro modo, fácil trabalharias até um só dia

de sorte a teres bastante até por um ano;

ligeiro irias o leme sobre a fumaça depositar, e findaria o trabalho dos bois e das mulas robustas.

(Trabalhos e dias, 40-46, trad. Christian Werner)

Ora, o que é figurado negativa e ironicamente também aqui é uma vida frugalíssima, que pode se contentar, como alimento, com plantas não cultivadas e apenas colhidas, mas cujo pretenso ganho seria (em contraposição à agricultura ou à navegação) a facilidade e a não-necessidade de trabalhar a terra ou navegar. ${ }^{14}$ Poderíamos lembrar aqui da perspectiva do agricultor e do navegador (e, por extensão, também do colonizador) que dá forma ao modo como é vista a ilha das Cabras por Odisseu (cf. Odisseia IX, 122-141), assim como da valorização por Odisseu, em sua resposta a Eurímaco (que lhe oferece o emprego de mero cuidador de uma propriedade sua), de duas atividades eminentemente viris: a agricultura e a guerra (cf. Odisseia XVIII, 366-380, e também O econômico, cap. IV e V, de Xenofonte). ${ }^{15}$

Assim, a imagem de uma humanidade primitiva que não necessita trabalhar a terra (ou exercer qualquer outra atividade, como a pecuária, a navegação ou a guerra) para comer, em que pese o fascínio que pode trazer a inércia fácil para aqueles cansados dos sofrimentos da guerra e da navegação (como os companheiros de Odisseu que comem o "lótus"), é inteiramente negativa para uma concepção heroica do homem, como a da Odisseia, que pressupõe sempre (mesmo se ambicionando o reconhecimento público do poder em uma rede de relações de reciprocidade entre nobres, que inclui tradicionalmente o banquete) a agricultura combinada com a pecuária (as duas formas propriamente humanas de obtenção de víveres e produção de riquezas a partir da natureza), ${ }^{16}$ e o pão de trigo e a carne assada de animais domésticos sacrificados como comida.

É, portanto, a um tipo de prazer passivo como este (o de poder não fazer nada senão comer o que é colhido), que pode ser associado negativamente o modo de vida dos Lotófagos, tal como o faz Heráclito Pôntico ao definir o "prazer" - ao largo do qual Odisseu passou,

14 “(...) mallow and asphodel, natural and uncultivated, may well have been the diet of mankind in the golden age long ago, when men were closer to the gods and before the invention of agriculture. Nowadays, however, the 'great benefit' in these weeds lies not in being good to eat, but on the contrary, in recognition that they offer a poor diet for human beings of the present." (Clay, 2003, p. 36-37).

15 “(...) when Odysseus describes the island offshore from the Cyclops (...), he describes it with a farmer's eye: its meadows, possible vineyards, and arable land with deep topsoil (9.116-51).” (Redfield, 2009 , p. 276). "When Odysseus, disguised as a beggar, is ironically offered a job hedging and ditching (...), he reacts with an angry challenge: if only there could be a test in reaping or ploughing, so that he could outfight them all (18.356-386)." (Redfield, 2009, p. 276).

${ }^{16}$ Ver, para uma compreensão mais abrangente do modo como este modelo econômico (baseado na agricultura combinada com a pecuária) persiste na Grécia clássica e mesmo depois, o livro de Timothy Howe, Pastoral Politics: Animals, Agriculture and Society in Ancient Greece (Howe, 2008). 
dominando-se - como "região lotófaga", tò Lōtophágon khōrion (Alegorias de Homero, cap. 70, 3), ou depois Xenofonte, na Anábase, quando quer arrancar os mercenários de uma vida fácil (que inclui também o sexo com mulheres bonitas), que os leva a se esquecerem do retorno: "Mas se aprendermos uma vez a viver sem nada fazer, a passar os dias na abundância, e a ter relações com as mulheres e moças dos Medos e dos Persas, que são belas e grandes, temo que, como os Lotófagos, nós esqueçamos o caminho para casa." (Anábase, III, 2, 25, tradução minha, negritos meus). ${ }^{17}$

\section{B. Os Lotófagos E OS EFEITos do "LÓtus"}

Resta, no entanto, comentarmos não só o episódio dos Lotófagos como um todo (e, mais especificamente, o insólito efeito do "lótus" sobre os três companheiros de Odisseu que o provaram), como também a sua posição e função no conjunto do relato das viagens maravilhosas de Odisseu (o que deixaremos para um segundo e conclusivo momento). Do ponto de vista das convenções narrativas das viagens de Odisseu na Odisseia, o episódio se organiza como um conjunto segundo um padrão conhecido, assim descrito por Irene de Jong em $A$ Narratological Commentary on the Odyssey (com apenas a parte 3 faltando): "1) chegada: aportagem e desembarque (83-85);2) atividades iniciais como o aprovisionamento de água, uma refeição e o sono (85-87); 3) exploração do novo território em busca de sinais de habitação (-); 4) envio de batedores para determinar a natureza dos habitantes (88-90); 5) confrontação perigosa (91-97); 6) resgate dos companheiros por Odisseu (98-102); 7) partida (103-105)." (de Jong, 2001, p. 230).

Mas do ponto de vista da recepção de um hóspede (ou estrangeiro) - ou seja: da cena típica de hospitalidade estudada por Steve Reece em The Stranger's Welcome $e^{18}$ - poderíamos observar que, apesar de os Lotófagos não serem hostis ou assassinos, uma série de elementos básicos estão ausentes: a introdução na casa (pois não há casa nem interiores descritos); a designação de um assento (pois não há menção de cadeiras); a preparação da mesa e eventualmente a lavagem das mãos (pois não há menção de mesas nem de abluções); após a oferta de comida e bebida (único elemento presente), uma conversa para a identificação do hóspede (pois não há menção de diálogos e nem podemos saber se os Lotófagos falavam uma língua qualquer); a oferta de presentes de hospitalidade e a preparação do envio (pois é Odisseu quem resgata os companheiros, que lá teriam ficado e jamais partiriam, se não fosse assim).

Esta compressão narrativa devida ao foco exclusivo na comida (e em seus efeitos) é, no entanto, prenunciada pela ênfase dada ao elemento da comida nos versos introdutórios que descrevem a primeira refeição em terra ("e rápido almoçaram junto às ágeis naus, os companheiros. / Mas depois que partilhamos tanto do pão quanto da bebida") e que tentam

\footnotetext{
${ }^{17}$ Também é uma suposta inatividade ou inércia total que está na base da seguinte representação dos Lotófagos proposta no tratado Sobre coisas admiráveis de se ouvir atribuído a Aristóteles: "Os Lotófagos dormem por seis meses." (apud Page, 1973, p. 6, tradução minha).

${ }^{18}$ Ver sobretudo a introdução ("Introduction") e o primeiro capítulo ("The Conventions of the Homeric Hospitality Scene") de The Stranger's Welcome. Oral theory and the Aesthetics of the Homeric Hospitality Scene (Reece, 1993, p. 1-46).
} 
definir pela alimentação (dizendo justamente o que eles não são) a natureza desconhecida dos "homens" daquela terra ("quais seriam os homens que sobre este solo comem o pão"), destacando pela repetição de sîtos ("trigo", "pão" ou "comida”) o elemento básico suposto da alimentação humana, que (pressupondo também a cultura de cereais) não será encontrado entre este povo estranho.

E naquele que é, assim, o único elemento básico presente (e que é central) em uma cena de recepção: a oferta de comida antes da identificação, ${ }^{19}$ temos também um desvio da norma, primeiramente pela natureza mesma da comida, que está completamente fora da tríade que forma o padrão homérico humano de alimentação: o pão (de centeio ou de trigo), a carne assada de um animal doméstico sacrificável e o vinho misturado com a água, sendo este o único caso em Homero de um povo que come "uma comida floral" e que se alimenta do "fruto sabor-de-mel" do lōtós ("lótus"?), o que poderia lembrar um tipo rude de vegetarianismo. Por outro lado, não sabemos (por simplesmente nada ser mencionado) se e como os Lotófagos preparavam o "lótus" (se operavam com o fogo culinário: a assadura ou o cozimento), nem se eles consumiam também outros tipos de alimentos. O silêncio também nos impede de saber o que eles fariam além da oferta do compartilhamento desta comida floral e do seu consumo, como se induzindo a pensar que nada, figurando (com seu vácuo) uma vida desocupada e sem nenhuma atividade específica, ou inteiramente centrada no consumo do "lótus".

O segundo desvio da norma, este sim decisivo, estaria no efeito - que poderíamos chamar de - "psicotrópico" produzido por esta "comida floral": a perda da vontade de dar notícias ou retornar, que impediria, pela mutação ou anulação forçada da "vontade" do hóspede, a continuação da viagem..$^{20}$ Seria útil e necessário aqui observar primeiro, segundo uma sugestão perspicaz de M. Rousseaux (no hoje já famoso artigo "Ulysse et les mangeurs de coquelicots"), que o efeito preciso do "lótus", tal como descrito por Odisseu, é não exatamente o da perda da memória (ainda que o esquecimento do retorno seja uma ameaça genérica: "que nenhum, do lótus comendo, do retorno se esquecesse", v. 102), mas o da perda da vontade de dar notícias ou retornar ("não mais de novo queria (éthelen) dar notícias suas, nem retornar", v. 95) ou o da vontade de ali ficar "pastando o lótus" (fórmula que é usada na Ilíada para cavalos pastando, Il. II, 776, e que pode indicar aqui

\footnotetext{
${ }^{19}$ Para um comentário filológico mais preciso sobre a "cena típica" (segundo Walter Arend) ou o "tema" (segundo Albert Lord) do banquete na Odisseia, ver o subcapítulo "The Feast Theme" do já citado capítulo 7 de Traditional Oral Epic de J. M. Foley (1990, p. 265-277), que, por contraste, pode explicitar o quanto há de anômalo e não tradicional neste "banquete" de lótus oferecido pelos Lotófagos.

${ }^{20}$ Por outro lado, o risco mais genérico de provar uma comida estranha e nociva (tema aparentemente tradicional em histórias de viagens ou de contatos com povos estranhos) é sugerido por Gabriel Germain, em Genèse de l'Odyssée, a partir de uma citação de La mentalité primitive de Lévy-Bruhl: "Un aliment nouveau donnera à craindre au primitif qu'il ne soit le véhicule d'un maléfice mortel et rien ne pourra le persuader d'y goûter. En second lieu, manger n'est pas seulement, pour lui, la satisfaction d'un besoin élémentaire. (...) La substance de l'aliment s'incorpore à celle même de l'homme qui la consomme: la participation est si intime que les deux substances ne font plus qu'une." (Germain, 1954, p. 225).
} 
alguma animalidade) e se esquecer do retorno ("mas ali tinham vontade de (boúlonto), com os homens lotófagos/ o lótus pastando, permanecer e do retorno se esquecer", (v. 96-97), no que seria, então, antes uma abulia, cuja consequência, essa sim, seria o esquecimento do retorno (cf. Rousseaux, 1971, p. 344).

Esta atenção textual já estava, por outro lado, presente entre os escólios H.Q. da Odisseia que, ao comentarem a expressão nóstou te lathésthai do verso 97 do canto IX, dizem: “(...) não como se o loto criasse o esquecimento, mas como se, devido ao prazer, eles desprezassem o retorno. (...) Pois não se esqueceram, mas descuidaram completamente (ou gàr epeláthonto, allà katèmélesan)." (Dindorf, 1855, p. 414).

Ora, se - diferentemente do que ocorre com um dos elementos da "mistura" dada por Circe aos companheiros de Odisseu ou com o que Helena mistura ao vinho servido a Menelau, Telêmaco e Pisístrato - o "lótus" jamais é chamado de phármakon ("droga"), o seu efeito sobre os companheiros de Odisseu que o provam é totalmente inusitado para qualquer outra comida ingerida por humanos na Odisseia, sendo, por isso, identificado por vários comentadores como o (ou o semelhante ao) de uma droga.

Baudelaire, citado por M. Rousseaux logo no começo de seu artigo (que propõe para lōtós a tradução por "coquelicot", uma espécie ordinária de papoula, cujo efeito tóxico seria semelhante ao do ópio ${ }^{21}$ ) como uma espécie de inofensiva epígrafe, ${ }^{22}$ diz o seguinte,

${ }^{21}$ As razões algo arbitrárias e fantasistas que levaram primeiramente M. Rousseaux a identificar o "lótus" com esta espécie ordinária de papoula, o "coquelicot" [“crescimento espontâneo em todos terrenos (na região mediterrânea que nos ocupa) e cultura fácil; floração ambígua onde, bem antes da queda das pétalas, a cápsula porta-grãos, como um fruto já formado, atinge seu pleno desenvolvimento; nocividade destas 'cabeças' ainda verdes, cheias de grãos brancos de um suco cujo poder, soporífico e sedativo em dose fraca, pode provocar as perturbações do ópio sob forma concentrada” (Rousseaux, 1971, p. 348, tradução minha)], poderiam de algum modo ser aplicáveis também ao haxixe (que, por sua denominação, ainda permitiria compreender o seu uso para designar uma planta forrageira), segundo esta primeira descrição de Baudelaire em "Le poème du hachisch" (do livro Les paradis artificiels): "O haxixe (ou erva, isto é: a erva por excelência, como se os Árabes tivessem querido definir em uma palavra a erva, fonte de todas as voluptuosidades imateriais) tem diferentes nomes, segundo sua composição e o modo de preparação que ele sofreu na região onde foi colhido: na Índia, bangi; na África, teriaki; na Argélia e na Arábia feliz, madjund, etc. Não é indiferente colhê-lo em qualquer época do ano; é quando ele está em flor que ele possui sua maior energia; as extremidades floridas são, por consequência, as únicas partes empregadas nas diferentes preparações sobre as quais temos algumas palavras a dizer." (Baudelaire, 1980, p. 235, a tradução e os negritos - para destacar os temas aqui em questão - são meus). Mas, apesar de sedutora, esta aproximação também é indemonstrável e arbitrária. ${ }^{22}$ A passagem citada, que demonstra o conhecimento do episódio por Baudelaire, encontra-se no $29^{\circ}$ pequeno poema em prosa de Le Spleen de Paris: "Une béatitude sombre, analogue à celle que durent éprouver les Mangeurs de Lotos, quand, débarquant dans une île enchantée... ils sentirent naitre en eux... le désir de ne jamais revoir leurs pénates, leurs femmes, leurs enfants, et de ne jamais remonter sur les hautes lames de la mer." (Baudelaire, apud Rousseaux, 1971, p. 333). É curioso, no entanto, que, mesmo após ter descrito com precisão o efeito da ingestão de "lótus" sobre os companheiros de Odisseu (a perda da vontade) e ter proposto que o "lótus" é uma espécie ordinária de papoula (com 
descrevendo os efeitos pós-embriaguez (ou a ressaca) do haxixe, na conclusão moralizante ("V - Morale") do grande ensaio "Le poème du hachisch" que abre o livro Les paradis artificiels: "A vontade, sobretudo, é atacada, de todas as faculdades a mais preciosa. Diz-se, e é quase verdade, que esta substância não causa nenhum mal físico, nenhum mal grave, ao menos. Mas pode-se afirmar que um homem incapaz de ação, e capaz somente de sonhar, se comportaria realmente bem, mesmo se todos os seus membros estivessem em bom estado? Ora, nós conhecemos bastante a natureza humana para saber que um homem que pode, com uma colherada de doce, obter instantaneamente todos os bens do céu e da terra, não ganharia jamais a milésima parte deles pelo trabalho. ${ }^{23}$ (...) Balzac pensava, sem dúvida, que não existe para o homem maior vergonha, nem mais vivo sofrimento, do que a abdicação da vontade." ${ }^{24}$ (Baudelaire, 1980, p. 255, tradução minha). Mas, segundo Baudelaire (em seu resumo de Un mangeur d'opium de Thomas de Quincey), este efeito se faz sentir igualmente naquele que passa a consumir com regularidade o ópio: "Horrível situação! Ter o espírito formigando de ideias e não mais poder atravessar a ponte que separa as campanhas imaginárias do devaneio das colheitas positivas da ação. (...) Abominável encantamento! Tudo aquilo que eu disse sobre a diminuição da vontade no meu estudo sobre o haxixe é aplicável ao ópio. Responder cartas? Trabalho gigantesco, adiado de hora a hora, de dia a dia, de mês a mês." (Baudelaire, 1980, p. 281, tradução minha).

Mas o recurso de pensar sobre um estado alterado de ânimo (ou consciência) a partir do consumo de uma planta (no caso do haxixe ou do ópio, preparada) visa menos a uma identificação botânica precisa desta planta do que a uma identificação mais precisa da natureza deste efeito. Assim, alguém que, como James P. Holoka, admite não estar pensando em nenhuma improvável conexão deliberada entre o "lótus" e a "mescalina", usa - no breve artigo "Aldous Huxley and the Lotus Experience" - os efeitos da mescalina descritos por Aldous Huxley em The Doors of Perception para compreender melhor os efeitos do "lótus" sobre os companheiros de Odisseu, destacando em itálico na sua citação o que lhe parece o ponto crucial, "a perda da vontade" (e coincidindo, portanto, com a interpretação de M. Rousseaux): “"(...) a vontade sofre uma profunda mudança para pior. O tomador de mescalina não vê nenbuma razão para fazer nada de particular acha a maioria das causas pelas quais, em tempos ordinários, ele estava preparado para agir e sofrer, profundamente desinteressante." (Huxley, apud Holoka, 1982, p. 40, tradução minha). O que é mais importante, porém, é o modo como Holoka conecta

um efeito tóxico como o do ópio), M. Rousseaux jamais faça uma menção do efeito do ópio sobre a vontade de quem o consome regularmente, tal como descrito por Baudelaire no grande resumo de Un mangeur d'opium de Thomas de Quincey na segunda parte de Les paradis artificiels (cf. Baudelaire, 1980, p. 258-305).

${ }^{23}$ É possível lembrar aqui do quanto uma alimentação que é fornecida espontaneamente pela terra, como a malva e o asfódelo (ou os frutos da "lavoura dá-trigo" para a linhagem de ouro) em Trabalhose dias de Hesíodo, levaria a uma despreocupação total quanto ao trabalho da terra (ou ao da navegação). 24 “Eu o vi uma vez, em uma reunião onde estavam em questão os efeitos prodigiosos do haxixe. Ele escutava e questionava com uma atenção e uma vivacidade engraçadas. As pessoas que o conheceram adivinham que ele devia estar interessado. Mas a ideia de pensar contra a sua vontade o chocava vivamente." (Baudelaire, 1980, p. 255, tradução minha.) 
a descrição por Huxley destes efeitos análogos ao do lótus (“a perda da vontade”) com o tema mesmo do poema ("o retorno"), demonstrando o quanto eles são elementarmente destrutivos: "Os homens na Odisseia não estavam mais querendo (...) dar notícias ou retornar. O efeito do lótus é, assim, o de interromper, pela duração de sua ação, a 'vontade de retornar' - para a nau e, com isso, para a sua casa e sua terra. Isso é mais sinistro em uma épica devotada à busca heroica da casa.” (Holoka, 1982, p. 40, tradução minha).

Se, portanto, perder a vontade de retornar (ou de dar notícias suas) é destrutivo e fatal não só para uma história de retorno (como o é a Odisseia) como para um heroísmo que pressupõe a ação e um objetivo a ser atingido (enfrentando uma série de obstáculos e de sofrimentos), um estado passivo e de abandono (aqui em relação ao retorno), induzido pelo consumo do "lótus", seria altamente criticável para uma moral heroica. ${ }^{25}$ Se quiséssemos figurar, uma última vez, o fenômeno da perda (ou dissolução) da vontade a partir de descrições do efeito da mescalina, mas agora com uma perspectiva crítico-moral mais acentuada, seria útil recortar (e recordar) algumas observações de Henri Michaux sobre a quinta experiência com mescalina das oito publicadas na $2^{a}$ parte de L'infini turbulent: "A tentação de Santo Antônio, eu o sei agora, é a tentação da dissolução da vontade e da compostura. Em uma feminização do mundo o pecador se afoga contente. Gožo da deliquescência." "Com razão, o pântano, a lama, os detritos que escorrem são as imagens deste estado, em que se está, com efeito, colado e à deriva. Pecado (sim) contra si, contra seu personagem, contra sua nobreza, contra a ideia que se quer guardar de si... e (para um homem que tem religião) contra Deus. O demônio sedutor tomou o lugar, pois é-se seduzido a se deixar ir, ao indefinido deixar ir, ao infinito abandono. Sedução da dissolução.” (Michaux, 1984, p. 100 e 102 respectivamente, tradução minha).

Este efeito "psicotrópico" se coaduna aqui com o fato de que apenas uma ingestão do "lótus" (ou, no máximo, duas, se pensarmos como mais largo o tempo que leva Odisseu para estranhar o não retorno dos três companheiros) seria suficiente para criar definitivamente um desejo de continuar a consumi-lo (ou o que chamaríamos de dependência), como o mostra a reação dos companheiros de Odisseu que o provaram, quando ele decide salvá-los: "A estes, que choravam (klaíontas), eu conduzi até as naus por força" (v. 98), assim como $\mathrm{o}$ ato de força ou violência necessária da parte de Odisseu indica o quanto eles poderiam estar resistindo: "e nas naus côncavas sob os bancos os prendi, arrastando (erússas)." Isso poderia, por sua vez, figurar, de uma maneira extrema ou hiperbólica (que a experiência

\footnotetext{
${ }^{25}$ Do ponto de vista moral (e também médico) a disseminação do consumo de drogas psicotrópicas na contemporaneidade seria também criticável por querer ingenuamente recusar a angústia e a cota inevitável de sofrimento presentes na ação humana, sem a qual o próprio conceito de felicidade (pensada como um mero estado passivo de bem-estar e prazer) se torna inteiramente discutível. Ver para tanto o lúcido artigo de G. M. Carstairs "A Land of Lotus-Eaters?” (1969), em cujo resumo inicial podemos ler: "With the popularization of the psychotropic drugs (...) a peculiar aberration has entered into public thinking: everyone nowadays expects to be happy. Pills have come to be regarded as a means to do away with the everyday anxieties and pain that have long served as spurs to human progress by leading to constructive action." (Carstairs, 1969, p. 1576).
} 
propriamente não confirma), o modo mais rápido e fatal como pode se dar a adicção a drogas pesadas como o ópio, a morfina ou a heroína. ${ }^{26}$ Mas na Odisseia nenhuma menção direta é feita a qualquer efeito de prazer, sendo este dedutível apenas pelo contraste opositivo do sofrimento causado pela privação do "lótus". Seria talvez a partir de um tal tipo de dedução (possível, mas não necessária) que a exegese alegórica moralizante de um Heráclito Pôntico, buscando um segundo e oculto sentido para a narrativa, sugere o prazer (o primeiro dos vícios detestados por Odisseu) como o que significariam figuradamente os Lotófagos: "O prazer (Hèdonén), esta região lotófaga (tò Lōtophágon khōrion), que cultiva um estranho gozo, (prazer) ao largo do qual Odisseu, dominando-se, passou navegando." (Alegorias de Homero, cap. 70, 3, tradução minha).

Em um episódio caracterizado por uma máxima compressão narrativa, seria importante ainda assinalar o que compõe a cena, mas permanece não dito explicitamente: a ausência de reação dos Lotófagos face ao ato de força de Odisseu para com seus companheiros, a qual parece de algum modo confirmar sua primeira caracterização deles como inofensivos: "mas não pensaram os Lotófagos morte para os companheiros/ nossos" (v. 72-73), mas indica também uma espécie de indiferença ou sentimento de não-comunidade (ou não-simpatia direta) com os hóspedes que - contrariamente às regras de hospitalidade deixam a sua terra não exatamente desejando fazê-lo, mas à força. Mas esta mesma indiferença pode ser signo também da ausência de um plano qualquer de apropriação ou escravização destes três companheiros de Odisseu, que talvez fosse inútil em uma terra onde a dimensão do trabalho (para obtenção dos meios de vida) está ausente. Esta ausência de reação dos Lotófagos é, no entanto, insuficiente (dado o silêncio do narrador) para nos figurarmos se também eles (velhos habitués) sofreriam, como os que estão experimentando o "lótus" pela primeira vez, o mesmo efeito de abulia ou perda da vontade (que obviamente não poderia ser a da do retorno, uma vez que eles já estão em sua terra).

Um tal efeito de uma comida (a única na Odisseia a funcionar ela mesma como "droga", apesar de o termo phármakon não aparecer) lembra não tanto o da beberagem ou

\footnotetext{
${ }^{26}$ O testemunho, por exemplo, de um "especialista” como William Burroughs (no romance Junky) é claro e concludente: "Demora pelo menos dois meses, com duas aplicações diárias, para se ficar realmente dependente. E ninguém sabe de fato o que é fissura por droga pesada até passar por vários períodos de dependência. Eu demorei quase quatro meses para ficar dependente pela primeira vez, e, mesmo então, os sintomas da privação foram suaves. Não acho exagero afirmar que é preciso um ano e várias centenas de injeções para se produzir um verdadeiro viciado." Mas a exposição crua dos motivos que levam à dependência - assim como a percepção instantânea e fatalista do vício já instalado - ecoam os efeitos abúlicos do "lótus" e a figura hiperbólica de uma adicção letal por uma única ingestão: "Bem, você se vicia em entorpecentes quando não tem motivações fortes que apontem em outras direções. A droga pesada ganha por desistência. (...) Ninguém começou a usar drogas por algum motivo especial. Apenas foram tomando seus picos até se verem fisgados. Quem nunca foi viciado não consegue entender o que significa precisar da droga pesada com a urgência do vício. Ninguém decide virar viciado. Certa manhã o sujeito acorda fissurado e pronto - é um viciado." (Burroughs, 1984, p. 15, os negritos - para destacar os temas aqui em questão - são meus).
} 
mistura (o kukeón) de Circe que, incluindo phármaka lugrá, "drogas funestas" (cf. Od. XII, 236), transforma fisicamente os companheiros de Odisseu em porcos, mas não modifica o seu espírito (cf. Od. XII, 239-240), quanto o da "droga" (phármakon) misturada ao vinho por Helena, cujo efeito sobre os comensais é manifestamente analgésico em relação ao ânimo ("a anulação da dor e da ira e o olvido de todos os males", $O d$. IV, 221), permitindo conter o choro lutuoso dos convidados (inconveniente em um banquete), quando da rememoração de Odisseu desaparecido. Mas este efeito do "lótus", por outro lado, se aproxima do da mistura de Circe, porque em ambos os casos a modificação da identidade daqueles companheiros de Odisseu que os provam implica uma renúncia forçada do retorno, constituindo (da parte dos "anfitriões") uma infração às práticas da hospitalidade, ao impedir definitivamente $o$ "hóspede" (sem o seu consentimento em estado normal) de partir.

Assim, do ponto de vista de uma cena típica de hospitalidade, a oferta do "lótus" constitui não só uma transgressão por ser o único elemento (a comida oferecida) de uma cena maior, cujos outros elementos são todos suprimidos, como também (ao criar nos hóspedes o desejo definitivo de continuar comendo "lótus" e ali permanecer) por assimilar os "hóspedes" aos "anfitriões", destituindo-os de sua identidade anterior (e negando a sua alteridade), e por destruir, assim, fatalmente, a possibilidade básica de eles partirem (ou retornarem para casa), sem a qual o seu estatuto mesmo de "hóspedes" deixa de existir. Longe de ser um episódio menor e inofensivo (e recebendo o destaque de ser a primeira das aventuras maravilhosas de Odisseu), os Lotófagos, ao minarem, com os efeitos do "lótus", a vontade de agir (pensando mais genericamente no plano moral heroico) ou, mais precisamente (segundo a ação principal da Odisseia), a vontade de retornar, constituem uma ameaça extremamente perigosa e que seria fatal tanto para a identidade moral de Odisseu e de seus companheiros quanto para a própria narrativa da Odisseia, se todos dele tivessem provado (sem o recurso de um resgate), como os três enviados de Odisseu.

\section{O EPISÓdio dos lotófagos NaS VIAGENS DE OdisseU}

Seria, enfim, útil, para uma compreensão mais abrangente deste primeiro episódio das viagens maravilhosas de Odisseu (os Lotófagos), nos perguntarmos: (1) por sua função neste conjunto de histórias (que implica a de uma estrutura interna deste último) e, por sua vez, (2) pela função deste conjunto (uma narrativa de Odisseu, na primeira pessoa, para uma audiência de Feácios, de quem ele depende para poder retornar a Ítaca) no conjunto maior da história da Odisseia.

Em um brevíssimo resumo temático, seria possível dizer (começando pelo enquadramento maior) que a Odisseia, enquanto história do tipo genérico do "marido que retorna a sua casa" ("Homecoming Husband"), quando a mulher está para se casar com outro (cf. Bakker, 2013, p. 13-14), conta, em sua primeira parte, a história do "retorno" (nóstos) de Odisseu de Troia para Ítaca (e a da viagem e retorno de Telêmaco de Pilos e Esparta, para onde ele vai em busca de notícias do pai), e, na segunda, já em Ítaca (onde Odisseu se encontra com Telêmaco na cabana de Eumeu) a do seu "retorno" pleno a seu palácio (que passará pela matança dos pretendentes após a prova do arco), como senhor de seus bens, marido, 
pai, filho e rei. Enquanto história de viagens (tanto a de Odisseu quanto a de Telêmaco), em sua primeira parte, o poema será composto, sobretudo, por cenas típicas (ou desviantes em relação às típicas) de recepção do hóspede ou hospitalidade (que são unidades narrativas com elementos básicos dispostos em uma mesma ordem), que incluem a oferta de comida e a identificação (através de uma conversa) no contexto de um banquete, os eventuais banho e preparação do leito, o dom de presentes e o reenvio para seu destino. ${ }^{27}$ Mas é possível dizer também que a condição de mendigo estrangeiro em que será transformado Odisseu ao chegar em Ítaca permite retomar o tema da hospitalidade (e o do banquete), na segunda parte do poema, tanto em sua estadia transitória com Eumeu quanto em sua chegada a seu palácio ocupado pelos pretendentes, que consomem o seu patrimônio em um banquete contínuo, em uma situação anômala de hospitalidade já apresentada nos dois primeiros cantos e que só será resolvida no macabro banquete final, em dia de festa de Apolo, para a escolha do novo marido de Penélope através da prova do arco.

Ora, no momento em que Odisseu, tendo chegado à Feácia (depois de suas variadas viagens de Troia, passando pelos Cícones, até a ilha de Calipso), resolve se identificar, contando estas histórias para um auditório feácio, o seu desejo maior, depois de tudo pelo que passou, é o de retornar à sua família e à sua terra pátria, sendo substituído o seu temor inicial de uma má recepção pelos Feácios (a partir de indicações de Nausícaa e Atena) pelo temor inverso de uma excessivamente boa recepção, caso ele se deixasse ficar por mais tempo (banqueteandose) ou se casasse com Nausícaa (segundo a oferta de Alcínoo), o que atrasaria ou impediria o seu retorno. Assim, como veremos melhor ao examinar os "exemplos" (ou episódios) que compõem o conjunto desta longa narrativa para os Feácios, poderíamos dizer, com Glenn W. Most (no artigo "The Structure and Function of Odysseus' Apologoi”), que “(...) quaisquer outros significados que eles possam também ter, os apólogoi de Odisseu funcionam retoricamente, dentro de seu imediato contexto dramático, como uma diégeesis fornecendo exemplos para suportar um argumento cuja mensagem, se fosse colocada rudemente, seria 'Deixe-me ir para casa agora'.' (Most, 1989, p. 30, tradução e negritos meus).

A estrutura interna destas narrativas de viagem de Odisseu já é objeto de discussão entre os comentadores há algum tempo, sendo reconhecível um primeiro arranjo a partir da recorrência (três vezes) de um padrão ou unidade básica composta por dois primeiros episódios menores, seguidos por um terceiro maior e mais decisivo: 1) Cícones, Lotófagos e Ciclope; 2) Éolo, Lestrigões e Circe (Circe 1, Hades, Circe 2); 3) Sereias, Cila-Caríbdis, Trinácia, ${ }^{28}$ onde, porém, não só o desdobramento do episódio de Cila-Caríbdis (o obstáculo sendo Caríbdis, após o naufrágio e morte dos companheiros de Odisseu) não estaria presente,

\footnotetext{
${ }^{27}$ Ver o capítulo 9, "Hospitality Scenes and the Archictecture of the Odyssey", de The Stranger's Welcome, cf. Reece, 1993, p. 189-206.

28 "The most common suggestion has been that the adventures fall into groups of three, such that the third is longer and more challenging than the other two (...)." (Most, 1989, p. 21). Glenn Most cita, então, na nota 31 (1989, p. 21): "So e.g. F. Eichhorn, Homers Odyssee. Ein Führer durch die Dichtung (Göttingen, 1965), p. 63-64; Rothe, C., Die Odyssee als Dichtung und ihr Verbältnis zur Ilias (Padeborn, 1914), p. 72; and W. J. Woodhouse, The Composition of Homer's Odyssey (Oxford, 1930), p. 43-44."
} 
como também - e isso é o mais problemático - todo o episódio de Calipso. ${ }^{29} \mathrm{~A}$ estrutura interna que nos parece ser a mais precisa é a que foi sugerida por John D. Niles (em "Patterning in the Wanderings of Odysseus", cf. 1989, p. 51), a partir de Cedric Whitman (em Homer and the Heroic Tradition, cf. 1958, p. 288), e refinada por Glenn Most (1989, p. 22), ${ }^{30}$ como a de uma composição em anel geometrizável e simétrica, isolada por duas tempestades de dois dias, a primeira das quais (no retorno a partir de Troia) separa os Cícones dos Lotófagos, na entrada do mundo não-humano, e a segunda, na saída para um espaço de transição, separa Calipso dos Feácios que (os últimos a receber Odisseu) realizam seu transporte a Ítaca: em torno da Nékyia ("Descida ao Hades") se agrupam dois conjuntos de cinco episódios de estrutura concêntrica semelhante, dois episódios externos (no $1^{\circ}$ caso: Lotófagos e Circe; no $2^{\circ}$ : Sereias e Calipso), seguidos por dois episódios internos (no $1^{\circ}$ caso: Ciclope e Lestrigões; no $2^{\circ}$ : Cila e Caríbdis), em cujo centro estaria um último episódio (no $1^{\circ}$ caso: Éolo; no $2^{\circ}$ : Trinácia), em um desenho cuja parte final lembra o de dois garfos:

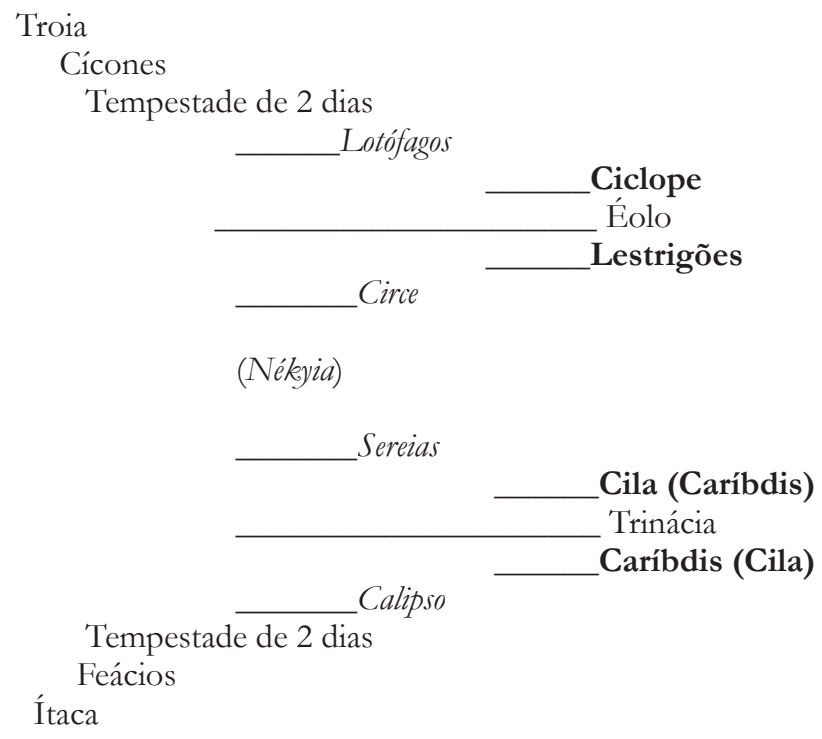

\footnotetext{
${ }^{29}$ Ver a nota 32 do artigo já citado de G. Most: "In fact, it seems to work only through the episode of Thrinacia: either one must accept that the Cattle of the Sun are followed by only two adventures (the return to Charybdis, and Calipso), or one must count as the third the Phaeacians (though they are in fact the audience of Odysseus' narrative, not part of its subject)." (Most, 1989, p. 21). G. Most nota também que o agrupamento em três elementos é uma espécie de fôrma mais genérica encontrável na poesia grega arcaica, e que, portanto, esclareceria pouco o que o arranjo do relato destas aventuras de Odisseu tem de singular (cf. Most, 1989, p. 21).

${ }^{30}$ Ver também a sua incorporação por E. J. Bakker em The Meaning of Meat and the Structure of the Odyssey (cf. 2013, p. 25-26), que, porém, reconhece também um outro padrão complementar, organizado como uma "busca", a partir das funções narrativas estabelecidas por Vladimir Propp, e que não consideraremos aqui.
} 
O que esta estrutura (já sugerida em um desenho ligeiramente diferente por J. D. Niles, cf. 1989, p. 51) também permite visualizar - a partir da interpretação de Glenn Most centrada no tema recorrente da hospitalidade, e já intuída por James Redfield no artigo “The Economic Man” (cf. 1983, p. 237-244) - são dois tipos contrários de riscos devidos ao excesso de hospitalidade (hyper-entertainment, segundo J. Redfield: o de permanecer muito tempo ou para sempre), figurado nos dois grupos externos em itálicos (Lotófagos e Circe; Sereias e Calipso), ou a extrema falta de hospitalidade (hypo-entertainment, segundo J. Redfield: o de ser comido pelo "anfitrião"), figurado nos dois grupos internos em negritos (Ciclope e Lestrigões; Cila e Caríbdis), ${ }^{31}$ que têm ao centro dois episódios que contêm infrações dos companheiros de Odisseu quanto a algum elemento básico da hospitalidade: no caso de Éolo, o desrespeito às boas condições (não abrir o odre de ventos) de um eficaz reenvio (pompé ) para casa; no caso das vacas do Sol, o desrespeito a um gado sagrado e imortal (propriedade do Sol), que não deve (sem o consentimento ou a oferta do dono) ser sacrificado e comido. ${ }^{32}$

Das duas duplas que figuram a extrema falta de hospitalidade (Ciclope e Lestrigões; Cila e Caribdis) deveria ser precisado que apenas a primeira o faz de maneira bem configurada, sendo, porém, todos estes seres monstruosos qualificáveis como antropófagos, isto é: como transgressores de uma proibição alimentar básica no mundo humano. Das outras duas duplas, que figuram o excesso de hospitalidade (Lotófagos e Circe; Sereias e Calipso), talvez fosse possível dizer - segundo seus elementos (a oferta de comida com efeito de droga: Lotófagos; a de comida misturada com droga ou um banquete contínuo: Circe; a do canto que enfeitiça e mata: Sereias; a de uma comida que imortaliza: Calipso; e ainda, no caso de Circe e Calipso, a do sexo) - que o seu elemento mais frequente, o da oferta de uma comida perigosa (ou droga), se mistura com o do sexo (com ninfas) e com o do canto, ${ }^{33}$ formando um conjunto

31 "Now what could be more the opposite of feeding your guests than feeding on your guests? And what could be more the opposite of sending your guests away when they want to go than causing them to linger on forever? The explanation for the arrangement of Odysseus' adventures is obvious: they confront him with the two extreme versions of bad hospitality (...). (...) Odysseus' apologoi are designed to define the proper duties of hospitality - negatively.” (Most, 1989, p. 25).

${ }^{32}$ Ainda que faça uma primeira descrição destes dois episódios, segundo dois outros elementos comuns (o sono fatal de Odisseu, abrindo espaço para a manifestação da insensatez de seus companheiros), G. Most depois sugere uma leitura possível dos dois episódios segundo duas funções (não respeitadas) da hospitalidade: “Indeed, perhaps even Odysseus' adventures with Aeolus and the Cattle of the Sun as well correspond to the general theme of the apologoi: Odysseus' crew might be violating one of the two crucial functions of hospitality, that of pompe $e^{\varepsilon}$, by opening the bag of winds on the way home from Aeolus' court, and the other one, that of feeding, by eating the forbidden Cattle of the Sun." (Most, 1989, p. 25, nota 51).

${ }^{33}$ G. Most descreve assim, neste grupo, a realização do efeito de privar alguém de seu retorno pela prolongação de sua estadia além do tempo conveniente para a sua partida: "The Lotus-eaters and Circe accomplish this with drugs (9.94-97), Circe again and Calypso with the erotic powers of a beautiful goddess $(1.13-15,55-57$; 10.347ff.), the Sirens with the magic of song (12.39-44, 183-193): there are many links among these various devices, drugs, eros, and songs, but the identity of their effect here is the most important." (Most, 1989, p. 23, negritos meus). 
que, por seus três elementos básicos, lembra o contexto (prazeroso e erótico) do banquete, que em Homero forma também o primeiro núcleo da hospitalidade.

Ora, seria possível dizer que, no relato destas viagens maravilhosas de Odisseu, ${ }^{34}$ assim como temos a figuração negativa da hospitalidade, temos também uma múltipla figuração negativa (ou não propriamente humana) da comida, cuja oferta e partilha constituem o primeiro elemento daquela. Em um conjunto em que está ausente a agricultura e o sacrifício (como apontado há algum tempo por Pierre Vidal-Naquet, cf. 1981), não só está figurado o regime animalesco extremo da antropofagia (Ciclope, Lestrigões, Cila e Caríbdis), como também o dos "vegetarianos" que comem plantas não cultivadas (o "lótus"), o do pastor antropófago que se alimenta de leite e queijos (que Odisseu e os companheiros também excepcionalmente comerão), o uso de uma mistura (com vinho, queijo, cevada, mel e uma droga) que transforma magicamente os homens que a comem em porcos, o uso do sangue cru de vítimas, do leite e do mel para apaziguar as "almas" dos mortos, o uso possível do néctar e da ambrosia como meio de imortalização, e ainda o da carne de animais caçados (que não são propriamente sacrificáveis e jamais fazem parte do menu tradicional, como as cabras selvagens na ilha das Cabras e o cervo na ilha de Circe) e o da de animais pescados (igualmente não-sacrificáveis e ausentes das mesas, como os peixes e as aves, na ilha de Trinácia), e, enfim, a ingestão da carne de animais sagrados e imortais (as vacas e ovelhas do Sol, também não sacrificáveis), que é religiosamente proibida.

Neste conjunto, os Lotófagos se caracterizam, ainda mais do que os pastores (que se alimentam de leite e queijos) ou do que os eventuais caçadores ou pescadores (que se alimentam de animais selvagens, aves e peixes), como aqueles que são os únicos a se alimentar unicamente de vegetais não plantados ("vegetarianos", mas não em sentido programático e religioso como para os pitagóricos e os órficos), em um modo de obtenção de alimentos (a coleta) que seria ainda mais preguiçoso e primitivo do que o dos pastores e o dos caçadores. E, como vimos antes, o efeito da comida oferecida pelos Lotófagos (o "lótus") é como o de uma droga - comparável ao do haxixe e do ópio (ou mesmo ao da mescalina) - que causa a perda da vontade (de dar notícias e de retornar) e também o desejo de apenas a consumir, ali permanecendo com eles (o que destruiria tanto o fundamento de atividade da ética heroica quanto a própria narrativa do retorno de Odisseu), assimilando inteiramente os hóspedes aos anfitriões e destruindo, assim, a sua identidade e condição mesma de hóspedes, em um caso extremo, e já logo o primeiro, de excesso de hospitalidade.

\footnotetext{
${ }^{34}$ Mesmo no caso dos Cícones, povo que habita a região da Trácia e é citado na Ilíada (II, 846) como aliado dos Troianos, único episódio não maravilhoso (antes da ultrapassagem do cabo Maleia) deste relato de Odisseu, o desastre vem concretamente do excesso de demora no banquete que se segue ao saque da cidade (cf. Odisseia IX, 43-46).
} 


\section{REFERÊNCIAS}

\section{[Textos antigos]}

ARISTOTELIS Politica. Edição O. Immisch. Leipzig: Teubner, 1909.

DINDORF, Wilhelm (ed.). Scholia Graeca in Homeri Odysseam tomus II. Oxonii: E Typographeo Academico, 1855.

ERODOTO. Storie, Volume primo (Libri I-II), testo greco a fronte. Traduzione di Augusta I. D’Accini, note di Daniela Fausti. Milano: Rizzoli, 1984.

ERODOTO. Storie, Volume secondo (Libri III-IV), testo greco a fronte. Traduzione di Augusta I. D’Accini, note di Daniela Fausti. Milano: Rizzoli, 1984.

HÉRACLITE. Allégories d'Homère. Texte établi et traduit par Félix Buffière. Paris: Les Belles Lettres, 1962.

HESIOD. Theogony, Works and Days, Testimonia. Edited and translated by Glenn W. Most. Cambridge, Mass.: Harvard University Press, 2006.

HESÍODO. Trabalhos e dias. Organização e tradução de Christian Werner. São Paulo: Hedra, 2013.

HOMERI Odyssea. Van Thiel, H. (ed.). Hildesheim: Olms, 1991.

HOMERI Opera tomi III et IV. Allen, T. W. (ed.). Oxford: Oxford University Press, 1987, 15th and 14th impression (1908).

HOMERO. Odisseia. Tradução de Frederico Lourenço; Introdução de Bernard Knox. São Paulo: Companhia das Letras/Penguin, 2011.

THÉOPHRASTE. Recherches sur les plantes, tome II, Livres III et IV. Texte établi et traduit par Suzanne Amigues. Paris: Les Belles Lettres, 2003.

THÉOPHRASTE. Recherches sur les plantes, tome IV, Livres VII et VIII. Texte établi et traduit par Suzanne Amigues. Paris: Les Belles Lettres, 2003.

XENOPHONTIS Opera omnia, vol. 3. Marchant, E. C. (ed.). Oxford: Clarendon Press, 1961 (1904).

\section{[TEXTOS, ESTUdos E LÉXICOS MODERNos]}

AREND, Walter. Die typischen Scenen bei Homer. Berlin: Weidmannsche Buchhandlung, 1933.

BAKKER, Egbert J. The Meaning of Meat and the Structure of the Odyssey. Cambridge: Cambridge University Press, 2013. 
BALLABRIGA, Alain. 2. Du Nil au couchant. In: Les fictions d'Homère. L'invention mythologique et cosmographique dans l'Odyssée. Paris: Presses Universitaires de France, 1998, p. 51-90.

BAUDELAIRE, Charles. Le poème du hachisch. In: Lesparadis artificiels. In: . Oewres complètes. Paris: Robert Laffont, 1980, p. 229-305, p. 232-257.

BAUDELAIRE, Charles. Le mangeur d'opium. In: Les paradis artificiels. In: . Oewrres complètes. Paris: Robert Laffont, 1980, p. 229-305, p. 258-305.

BURROUGHS, William. Junky - Drogado. Tradução de Reinaldo Moraes. São Paulo: Brasiliense, 1984.

CARSTAIRS, G. M. A Land of Lotus-Eaters?. American Journal of Psychiatry, v. 125, n. 11, p. 1576-1580, 1969.

CHANTRAINE, Pierre. Dictionnaire étymologique de la langue grecque. Histoire des mots, v. 3-4. Paris: Klincksieck, 1984 [1968].

CLAY, Jenny Strauss. Hesiod's cosmos. Cambridge: Cambridge University Press, 2003.

EDWARDS, Mark W. Type-Scenes and Homeric Hospitality. Transactions of the American Philological Association, v. 105, p. 51-72, 1975.

FOLEY, John Miles. The Feast Theme. In: 7. Thematic Structure in the Odyssey. In: Traditional Oral Epic. The Odyssey, Beowulf, and the Serbo-Croatian Return Song. Berkeley: University of California Press, 1990, p. 240-277, p. 265-277.

FOUCAUD, A. Un petit problème d'histoire grecque: Lotus et Lotophage. Revue d'bistoire de lapharmacie, v. 175, p. 422-424, 1962.

GERMAIN, Gabriel. Plantes magiques, nourritures d'oubli et toxiques sacrés. In: Genèse de l'Odyssée. Paris: Presses Universitaires de France, 1954, p. 216-231.

HEUBECK, Alfred. Books IX-XII. In: HEUBECK, A.; HOEKSTRA, A. A Commentary on Homer's Odyssey, v. II, Books IX-XVI. Oxford: Oxford University Press, 1989, p. 1-143.

HOLOKA, James P. Aldous Huxley and the Lotus Experience. The Classical World, v. 76, n. 1, p. 39-41, 1982.

HOUAISS, A.; VILLAR, M. S.; FRANCO, F. M. M. Dicionário Houaiss da língua portuguesa. Rio de Janeiro: Objetiva, 2001.

HOWE, Timothy. Pastoral Politics. Animals, Agriculture and Society in Ancient Greece. Claremont, California: Regina Books, 2008.

de JONG, Irene. A Narratological Commentary on the Odyssey. Cambridge: Cambridge University Press, 2001. 
LIDDELL, H. G., SCOT'T, R., JONES, H. S. A Greek-English Lexicon. Oxford: Clarendon Press, 1977.

LORD, Albert B. Chap. 4. The Theme. In: . The Singer of Tales. MITCHELL, S.; NAGY, G. (ed.). Cambridge, Mass.: Harvard University Press, 2000 (Second Edition), p. 68-98.

MICHAUX, Henri. Expérience V - Deuxième série. In: . L'infini turbulent. Paris: Mercure de France, 1984, p. 90-111.

MOST, Glenn W. The Structure and Function of Odysseus' Apologoi. Transactions of the American Philological Association, v. 119, p. 15-30, 1989.

NILES, John D. Patterning in the Wanderings of Odysseus. Ramus, v. 7, p. 46-60, 1989.

PAGE, Denys L. The Lotus-Eaters. In: . Folktales in Homer's Odyssey. Cambridge, Mass.: Harvard University Press, 1973, p. 1-21.

REDFIELD, James. The economic man. In: RUBINO, C. A.; SHELMERDINE, C. W. (ed.). Approaches to Homer. Austin: University of Texas Press, 1983, p. 220-247.

REECE, Steve. The Stranger's Welcome. Oral Theory and the Aesthetics of the Homeric Hospitality Scene. Ann Arbor: The University of Michigan Press, 1993.

ROUSSEAU, Philippe. Instruire Persès - Notes sur l'ouverture des Travaux d'Hésiode. In: BLAISE, F.; JUDET DE LA COMBE, P.; ROUSSEAU, Ph. (ed.). Le métier du mythe. Lectures d'Hésiode. Lille: Septentrion, 1996, p. 93-167.

ROUSSEAUX, M. Ulysse et les mangeurs de coquelicots. Bulletin de l'Association Guillaume Budé, $4^{\text {ème }}$ série, n. 3, p. 333-351, 1971.

SHAW, Brent. 'Eaters of flesh, drinkers of milk': the ancient mediterranean ideology of the pastoral nomad. Ancient Society, v. 13/14, p. 5-31, 1982/1983.

VIDAL-NAQUET, Pierre. Valeurs religieuses et mythiques de la terre et du sacrifice dans l'Odyssée. In: . Le chasseur noir. Formes de pensée et formes de société dans le monde grec. Paris: François Maspero, 1981, p. 39-68.

WHITMAN, Cedric H. Homer and the Heroic Tradition. Cambridge, Mass.: Harvard University Press, 1958. 